Proceedings

\title{
What's in Your Plate and Where Can you Find It? The Repre- sentativity of the Diet of Plant Eating Bat Diets on Molecular Data Bases ${ }^{\dagger}$
}

\author{
Hernani Fernandes Magalhaes de Oliveira 1,*, Ana Clara Vieira Teles ${ }^{2}$, Marina Mesquita Simoes ${ }^{2}$, \\ Elias Marques de Oliveira ${ }^{3}$ and Geraldo Freire-Jr ${ }^{2}$
}

Citation: de Oliveira, H.F.M.; Teles, A.C.V.; Simoes, M.M.; de Oliveira, E.M.; Freire-Jr, G. What's in Your Plate and Where Can you Find It? The Representativity of the Diet of Plant Eating Bat Diets on Molecular Data Bases. Proceedings 2021, 68, x. https://doi.org/10.3390/xxxxx

Published: date

Publisher's Note: MDPI stays neutral with regard to jurisdictional claims in published maps and institutional affiliations.

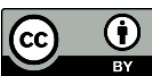

Copyright: (c) 2021 by the authors. Submitted for possible open access publication under the terms and conditions of the Creative Commons Attribution (CC BY) license (http://creativecommons.org/licenses/by/4.0/).
1 Universidade do Paraná -UFPR, Curitiba, PR, Brazil

2 University of Brasília-UnB, Brasília, DF, Brazil; email1@gmail.com (A.C.V.T.); email2@gmail.com (M.M.S.); email3@gmail.com (G.F.-Jr.)

3 Universitary Center ICESP, Brasília, DF, Brazil; email4@gmail.com

* Correspondence: oliveiradebio@gmail.com; Tel.: +55-(61)-3340-6313

+ Presented at the 1st International Electronic Conference on Biological Diversity, Ecology and Evolution, 1531 March 2021; Available online: https://bdee2021.sciforum.net/.

\begin{abstract}
DNA barcoding makes it possible to identify trophic relationships through traces of DNA present in animal faeces, allowing a more accurate description of mutualistic interactions, such as frugivory and pollination in tropical bats. However, success in this identification depends on the representativeness of the diet of these animal species in molecular databases. Poor molecular databases make it more difficult to identify plant DNA samples at the species level. Among the 21 existing bat families, a plant-based diet has evolved in only two of these families, Phyllostomidae (Neotropical) and Pteropodidae (Paleotropical), which represent about $28 \%$ of all bat species. Despite this, it is not known how much of the plant species present in their diet have sequences of different molecular markers, such as trnH, rbcL or ITS2, described and stored in molecular data bases, such as Bold Systems, one of the main molecular data bases to store DNA barcoding sequences. Thus, our study aims to compile the available data on the diet of frugivorous and nectarivorous bats from the families Pteropodidae and Phyllostomidae, and describe which molecular markers of plant species present in their diet have sequences stored in Bold Systems. In addition, we also intend to verify the countries of origin of these samples and the main depositary institutions. Thus, our study will provide an important basis in order to support future studies about the diet of frugivorous tropical bats based on molecular data.
\end{abstract}

Keywords: plantivorous bats; phyllostomidae; pteropodidae; trophic interactions; DNA barcoding; bold systems

\section{Introduction}

While the majority of the current 1,430 bat species distributed worldwide are insectivorous [1,2] a plant based diet is only found in two bat families: Pteropodidae and Phyllostomidae [3]. Both families have not only different evolutionary histories and distributions, but are also morphologically and ecologically very distinct [3]. Phyllostomidae is an Neotropical bat family with 221 species that use echolocation as one of their main ways to move across their environment, is morphologically very diverse and has evolved many different diet specializations, including carnivory and hematophagy, but where plants represent some of the main food items for the diet of most species [1,4]. On the other hand, Pteropodidae is a Paleotropical bat family with 191 species where the vast majority of species do not echolocate, but rely in their eye sight for navigating their environment $[1,5]$. Even though pteropodids might include insects in their diet, the main food items for all 
species are fruits and flowers $[3,6]$. Together, both families account for aproximately $29 \%$ of all bat species [1]. Thus, a plant based diet seems to have triggered a species radiation and diversification in bat species, since these two families represent only $9.5 \%$ of the 21 bat families in the planet [1].

Plantivorous bats perform important ecossystems services across the tropics, being responsible for the pollination and seed dispersal of more than 500 plant species [7]. However, identifying the food items in the diets of plant eating bats has remained challenging due to the problems associated with indentifying seeds, pulp, and pollen eggested in their faeces using traditional methods [8]. Since the development of molecular techniques to study trophic interactions, it has became possible to make a much more refined differentiation and identification of the food items present in different animal species. However, this identification still depends on the representativity of the food items present in the species diet on the molecular database which is used for this process. Bold sysems is one of the biggest molecular data basis for species identification worldwide, having more than 320,000 species deposited in their records $[9,10]$ In addition, it has the advantage of being a curated database, where each record is revised before their inclusion and maintenance [11].

The study of molecular trophic interactions for plantivorous animals has additional challenges in comparison with their animalivorous counterparts. Different than the molecular identification of animals, which is mostly based on the molecular markers COI and $16 \mathrm{~S}$ individually $[12,13]$, the molecular identification of plants is based on multiple molecular markers used simultenously in different combinations (matk, RBCL, trnh, ITS2) [14]. However, the representativity of these markers on moleculars databasis, such as Bold Systems, which is crucious for the correct identification of a plant species to the specie level, is not know for most plantivorous species, including those from the Phyllostomidae and Pteropodidae family. The goal of our study is to review the current literature in search of the records of plant species present in the diet of bat species from the Pteropodidae and Phyllostomidae families, and describe the representativity of the molecular markers mostly used to identify these plants (matk, RBCL, trnh, ITS2) in Bold Systems. In addition, we also intend to describe where the samples have been collected and the main institutions where they have been deposited worldwide (museums, collections, universities, etc.).

\section{Experiments}

\subsection{Literature Search}

We have performed an initial literature search on Scholar Google using the terms: "Phyllostomidae fruit plant species diet", "Phyllostomidae flower plant species diet", "Pteropodidae fruit plant species diet", and "Pteropodidae flower plant species diet". Afterwards, we will filter the articles to include in our initial database only those who have information about bat species from one of the targeted families and the presence of at least one plant species recorded to have been consumed by them. Additional information regarding the geographic coordinates of the location where the study was conducted and the main vegetation type will also going to be recorded.

\subsection{Molecular Data Basis Search}

The plant species that have been recorded in the diet of each bat species will be checked in the Bold Systems [10]. We will look for which molecular markers have been recorded for each plant species (matK, rbcL, trnH, ITS2), the origin country of the sample, and the main depository institution. These information will be used to understand for each bat species, genus, and subfamily, what are the main molecular markers, origin country.

\subsection{Statistical Analysis}


In order to generate a heat map of the origin countries where samples have been collected and the main depository institutions, we will use the R package tmaps [15]. We will also produce histograms to show the distribution of samples collected per country and the distribution of the number of samples per depository institution. All statistical analysis will be performed using $\mathrm{R}$ version 4.0.0 [16].

\section{Results}

We have found of 5000 references for the terms "Phyllostomidae fruit plant species $\operatorname{diet}^{\prime}, 2470$ for the terms "Phyllostomidae flower plant species diet", 4110 for the terms "Pteropodidae fruit plant species diet", and 1910 for the terms "Pteropodidae flower plant species diet", in a total of 13,490 articles about the diet of plantivorous bats.

\section{Discussion}

Even though phyllostomids have a much smaller area of distribution, but a similar number of species, in comparison with pteropodids, they have accounted for roughly half of the studies currently published about the diet of plantivorous bats $(55.37 \%)$. The Neotropics is one of the most diverse regions of the world in terms of plant species, with more than 118,000 described plant species [17]. However, due to the much greater distribution area of pteropodids, which include Southeast Asia, a region which is also highly diverse in plant species in relation to its size (50,000 plant species) [17], they are expected to have a lower diversity in plant species in their diet. Since the Afrotropics is particularly poorly sampled for many different taxa [18,19], and Central America has been responsible for a great quantity of plant sequences deposited in Bold Systems, there should be a much better representation of plant sequences from the diet of phyllostomids than pteropodids. However, we still need to confirm these information after the completion of the next steps of our study and make a refined description of the representativity of the diets of these.

\section{Conclusions}

The diet of phyllostomids and pteropodids are evenly distributed in the literature, with more papers directed for the diet of frugivorous than nectarivorous bats, likely due to the higher species richness of frugivorous bats. The representativity of the diet of the bats in the molecular databasis will be evaluated in the further steps of our study.

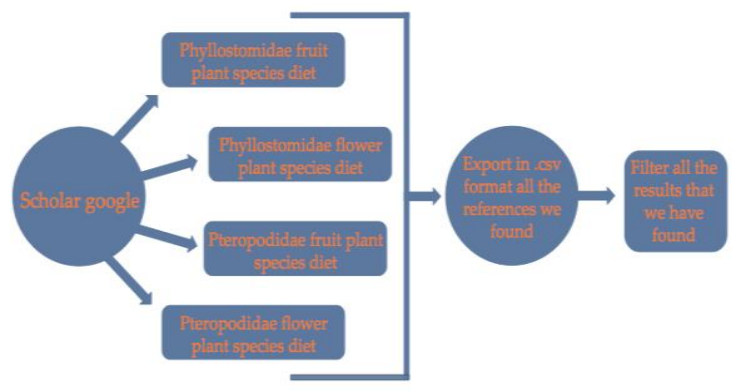

(a)

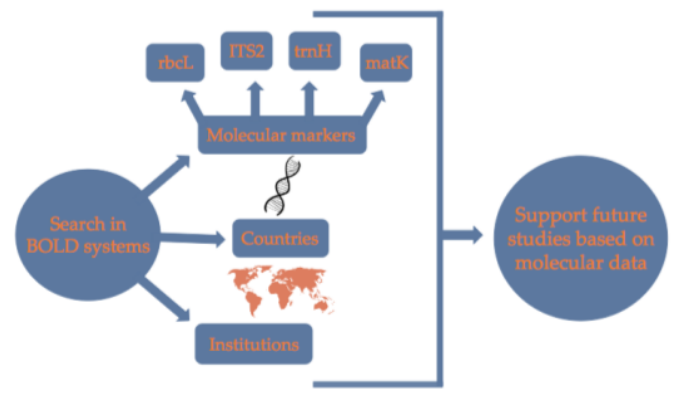

(b) 
Figure 1. Workflow of the literature search in order to review the current published articles about the species of plants present on the diet of plantivorous bats from the Phyllostomidae and Pteropodidae bat families (a), and subsequent steps to verify the representativity of these plant species on Bold Systems, the country origin of the samples and the institution where they have been deposited.

Author Contributions: H.F.M.d.O. conceived and designed the experiments; A.C.V.T., M.M.S., E.M.d.O. and. G.F.-J. have conducted the literature search; H.F.M.d.O. have led the writing of the article with inut from all authors. All authors have read and agreed to the published version of the manuscript.

\section{Institutional Review Board Statement:}

Informed Consent Statement:

Data Availability Statement:

Acknowledgments: we would like to thank the Brazilian government, more specifically CAPESPRINT, for the funding provided to H.F.M.d.O. for his postdoctoral scholarship, which has allowed for him to conduct and lead this research.

Conflicts of Interest: The authors declare no conflict of interest.

\section{Abbreviations}

The following abbreviations are used in this manuscript:

$\begin{array}{ll}\text { MDPI } & \text { Multidisciplinary Digital Publishing Institute } \\ \text { DOAJ } & \text { Directory of open access journals } \\ \text { TLA } & \text { Three letter acronym } \\ \text { LD } & \text { linear dichroism }\end{array}$

\section{References}

1. Mammal Diversity Database. Mammal Diversity Database (Version 1.31) [Data set]. Zenodo. 2020. Available online: http://doi.org/10.5281/zenodo.4139818 (accessed on).

2. Simmons, N.B. Order chiroptera. In Mammal Species of the World: A Taxonomic and Geographic Reference, 3rd. ed.; Wilson, D.E., Reeder, D.M., Eds.; Smithsonian Institution Press: Washington, DC, USA, 2005; pp. 312-529.

3. Muscarella, R.; Fleming, T.H. The role of frugivorous bats in tropical forest succession. Biol. Rev. 2007, 82, 573-590.

4. Dumont, E.R.; Davalos, L.M.; Goldberg, A.; Santana, S.E.; Rex, K.; Voigt, C.C. Morphological innovation, diversification and invasion of a new adaptive zone. Proc. R. Soc. B Biol. Sci. 2012, 279, 1797-1805.

5. Jones, G.; Teeling, E.C. The evolution of echolocation in bats. Trends Ecol. Evol. 2006, 21, 149-156.

6. Scanlon, A.T.; Petit, S.; Sternberg, L.D.S. Insectivory in Fijian flying foxes (Pteropodidae). Aust. J. Zool. 2013, 61, $342-349$.

7. Kunz, T.H.; De Torrez, E.B.; Bauer, D.; Lobova, T.; Fleming, T.H. Ecosystem services provided by bats. Europe 2011, $31,32$.

8. Clare, E.L. Molecular detection of trophic interactions: Emerging trends, distinct advantages, significant considerations and conservation applications. Evol. Appl. 2014, 7, 1144-1157.

9. Hajibabaei, M.; Singer, G.A.C.; Hebert, P.D.N.; Hickey, D.A. DNA barcoding: How it complements taxonomy, molecular phylogenetics and population genetics. Trends Genet. 2007, 4, 167-172, doi:10.1016/j.tig.2007.02.001.

10. Ratnasingham, S.; Hebert, P.D.N. BOLD: The Barcode of Life Data System (www.barcodinglife.org). Mol. Ecol. Notes 2007, 7, 355-364, doi:10.1111/j.1471-8286.2006.01678.x.

11. Arranz, V.; Pearman, W.S.; Aguirre, J.D.; Liggins, L. MARES, a replicable pipeline and curated reference database for marine eukaryote metabarcoding. Sci. Data 2020, 7, 1-8.

12. Hebert, P.D.; Stoeckle, M.Y.; Zemlak, T.S.; Francis, C.M. Identification of birds through DNA barcodes. PLoS Boil. 2004,2 , e312.

13. Ficetola, G.F.; Coissac, E.; Zundel, S.; Riaz, T.; Shehzad, W.; Bessière, J.; Taberlet, P.; Pompanon, F. An in silico approach for the evaluation of DNA barcodes. BMC Genom. 2010, 11, 434.

14. Li, X.; Yang, Y.; Henry, R.J.; Rossetto, M.; Wang, Y.; Chen, S. Plant DNA barcoding: From gene to genome. Biol. Rev. 2015, 90, 157-166.

15. Tennekes, M. tmap: Thematic Maps in R. J. Stat. Softw. 2018, 84, 1-39.

16. R Core Team. R: A Language and Environment for Statistical Computing; Version 4.0.0 ed. R Foundation for Statistical Computing: Vienna, Austria, 2019.

17. Raven, P.H.; Gereau, R.E.; Phillipson, P.B.; Chatelain, C.; Jenkins, C.N.; Ulloa, C.U. The distribution of biodiversity richness in the tropics. Sci. Adv. 2020, 6, eabc6228. 
18. Daniels, S.R.; James, N.C.; Gouws, G. Phylogeographic structure and continued surveys of a Vulnerable South African freshwater crab (Potamonautidae, Potamonautes lividus): Implications for the IUCN Red Listing of the Afrotropical fauna. Aquat. Conserve. 2020, 30, 2221-2239.

19. Sinsch, U.; Dehling, J.M.; Scheid, P.; Balczun, C. Molecular Diversity of Nematode Parasites in Afrotropical Reed Frogs (Hyperolius spp.). Divers 2020, 12, 265. 